\title{
Aerodynamic principles of shock-induced combustion ramjet engines
}

\author{
Kaifu Ma ${ }^{\mathrm{a}, \mathrm{b}}$, Zijian Zhang $^{\mathrm{a}, \mathrm{b}}$, Yunfeng Liu ${ }^{\mathrm{a}, \mathrm{b}, *}$, Zonglin Jiang ${ }^{\mathrm{a}, \mathrm{b}}$ \\ a School of Engineering Science, University of Chinese Academy of Sciences, Beijing 100049, China \\ ${ }^{\mathrm{b}}$ Institute of Mechanics, Chinese Academy of Sciences, Beijing 100190, China
}

\section{A R T I C L E I N F O}

\section{Article history:}

Received 3 October 2019

Received in revised form 3 March 2020

Accepted 9 March 2020

Available online 9 June 2020

Communicated by Zhao Dan

\section{Keywords:}

Scramjet engines

Shock-induced combustion ramjet engines

Supersonic combustion

Chapman-Jouguet detonation

\begin{abstract}
A B S T R A C T
The shock-induced combustion ramjet engine is the most favorable air breathing propulsive system and a suitable option for high-speed flight. In this paper, theoretical analysis and numerical simulations were conducted to study the thrust performance of shock-induced combustion ramjet engines. Firstly, the propulsive performance of supersonic combustion ramjet engines was theoretically analyzed by using the Chapman-Jouguet detonation theory. Then, the aerodynamic principles of shock-induced combustion ramjet engines were put forth on the basis of the theoretical analysis results. Finally, a full-scale shock-induced combustion ramjet engine was designed according to the aerodynamic principles. Twodimensional numerical simulations were conducted to simulate its combustion flow field and propulsive performance. The numerical results demonstrate the correctness and application of the theoretical aerodynamic principles.
\end{abstract}

(C) 2020 Elsevier Masson SAS. All rights reserved.

\section{Introduction}

The supersonic combustion ramjet (scramjet) engine has been expected to be one of the most promising propulsion systems for hypersonic air-breathing vehicles [1,2]. Scramjets have the potential to reduce the costs of accessing to space by taking air from atmosphere as an oxidizer. However, although many countries have investigated scramjets during the past 60 years, there is still a long way to go [3-10]. There are many complex theoretical and technical issues that still need to be explored and overcome to make scramjets operable for hypersonic flight. The thrust and supersonic combustion oscillation are two crucial aerodynamic issues that need for further study [3].

The first aerodynamic issue is that scramjets do not have enough thrust $[3,4]$. We do not know theoretically the method to increase its thrust effectively and the crucial parameters influencing the thrust. For example, the studies on scramjets at the French Aerospace Lab (ONERA) were stopped at 1972 due to the difficulty of the propulsive balance of an air-breathing hypersonic vehicle. For this reason, they made the decision to concentrate efforts on rocket engines. Although the activities of scramjets at ONERA were renewed in 1992, propulsive balance still remains to be a key issue for the development of air-breathing hypersonic vehicles [7].

\footnotetext{
* Corresponding author at: Institute of Mechanics, Chinese Academy of Sciences, Beijing 100190, China.

E-mail address: liuyunfeng@imech.ac.cn (Y. Liu).
}

The second issue is the supersonic combustion oscillation, which can cause the engine unstart. Researchers usually think that the engine unstart is mainly caused by shock-induced boundary layer separation in the combustor. But Laurence et al. [11,12] and Oh et al. [13] observed the shock waves propagating upstream in the isolator in the experiments and numerical simulations, respectively. Laurence et al. observed experimentally the shock wave propagating upstream with an absolute velocity of about $1900 \mathrm{~m} / \mathrm{s}$, which is very close to the Chapman-Jouguet (C-J) detonation velocity of $\mathrm{H}_{2}$ /Air mixture. In this case, the turbulence, diffusion, viscous, and heat conduction processes in ODEs are less important than that of scramjets. Their experimental results demonstrate that the engine unstart is caused by flow choking instead of the boundary layer separation [10-12]. The sonic combustion in the combustor of scramjet engines determines the upper limits of the equivalence ratio and thrust.

To the best knowledge of the authors, the theoretical analysis on propulsive performance of scramjet engines is difficult and rare in publications. The theory of one-dimensional heat-addition flow was first proposed by Tsien [14] in 1949 in order to study the propulsive performance of scramjet engines. This is the only theory that can be used to estimate the performance of scramjet engines up to now [15-17]. However, this theory is based on a steady-state reactive flow field and cannot predict the unsteady phenomena in the combustor of scramjets [18-21]. If the heat release in the combustor is violent, the pressure rise caused by combustion will produce shock waves in the confined space. The shock-shock interaction will enhance the strength of the leading shock wave [21]. The shock train propagates upstream to the inlet of aircraft. There- 
fore, this theory of steady combustion flow field cannot predict the shock waves in the isolator.

In the present study, the propulsive performance of scramjet engines is theoretically analyzed for the first time by the using C-J detonation theory. It is known that the C-J detonation is the strongest detonation wave produced by combustion. Therefore, the upper limit, critical characteristics, and propulsive performance of scramjets can be obtained [22]. Secondly, the aerodynamic design principles of shock-induced combustion ramjet (shcramjet) engines are put forth based on the theoretical analysis results. The shockinduced combustion ramjet engine has its advantages compared with the scramjet engine in high Mach number flight regimes $[23,24]$. Finally, a full-scale shcramjet engine is designed according to these principles. Two-dimensional numerical simulations are conducted to simulate its propulsive performance. The numerical simulation is not only the application but also a demonstration of the theoretical analysis results.

\section{Theoretical analysis of propulsive performance}

\subsection{Theoretical model of C-J detonation engine}

The schematic of scramjets is shown in the upper half of Fig. 1. It consists of six main parts: the forebody, internal inlet, isolator, combustor, internal nozzle, and aftbody. The supersonic combustion in the combustor produces pressure rise related to combustion in the confined space. The pressure rise in the combustor produces a series of shock waves, which oscillates in the isolator. The shockshock interaction enhances the strength of the leading shock wave [21]. If the velocity of the leading shock wave is faster than the incoming flow, it will move upstream out of the inlet. Thus, the unstart of scramjets occurs.

In order to study the characteristics of the shock waves and the propulsive performance of scramjets, we put forth a onedimensional physical model, as is shown in the lower half of Fig. 1. The flow field of scramjets can be simplified as two shock waves and one flame front. The flow direction is from left to right. The primary shock wave SW corresponds to the shock wave at the inlet. It can be an oblique shock wave or a normal shock wave. The secondary shock wave SW' represents the shock waves in the isolator. The flame front is considered to be the supersonic combustion flame in the combustor. Therefore, this simplified model can analyze the key mechanisms of scramjets. However, how to analyze the strength of the shock wave SW' quantitatively is a very difficult problem up to date. In this study, the classical C-J detonation theory is used to analyze the shock wave SW'. The shock wave SW' can be considered as a C-J detonation under thermal choking conditions, which is one of the critical conditions of the scramjets.

In this study, only the heat addition of scramjets is analyzed, while the geometry variation and boundary layer separation are not considered. The reason is that the combustion in the combustor of scramjets can be considered as constant-volume combustion and $\mathrm{C}-\mathrm{J}$ detonation theory can be applied to predict the flow field quantitatively. As a result, the supersonic combustion flow field of scramjets can be controlled according to the theoretical analysis. However, there is no theory to quantitatively predict the influence of the geometry variation and boundary layer separation. Therefore, we cannot control them and have to eliminate and avoid them in operations.

The theoretical physical model of C-J detonation engine is shown in Fig. 2. It consists of three parts: the straight isolator, straight combustor and divergent nozzle. The premixed combustible mixture in the isolator moves from left to right. Its static pressure, static temperature, velocity, and Mach number are $P_{1}$, $T_{1}, U_{1}$, and $M_{1}$, respectively. A C-J detonation wave forms in the combustor and propagates from right to left. The velocity and

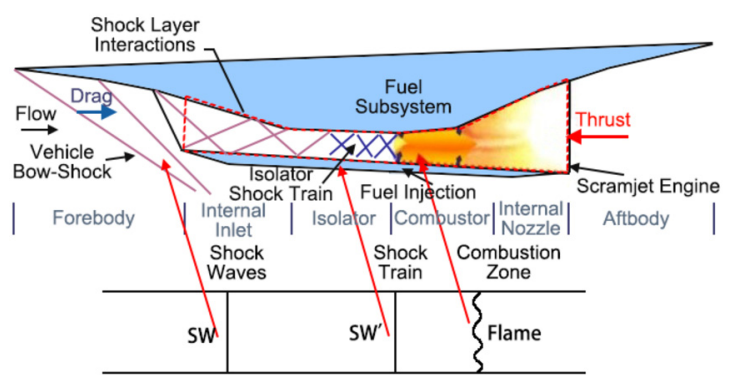

Fig. 1. The schematic of scramjets and the physical model.

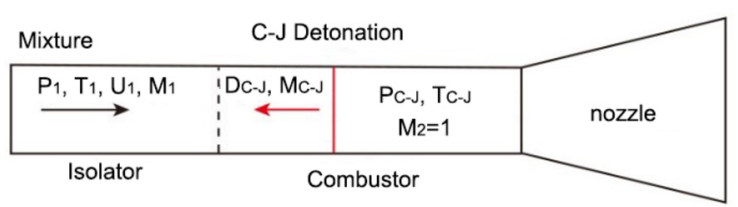

Fig. 2. Theoretical model of C-J detonation engine.

Mach number of the C-J detonation wave are $D_{\mathrm{C}-\mathrm{J}}$ and $M_{\mathrm{C}-\mathrm{J}}$, respectively. The pressure and temperature of detonation products are $P_{\mathrm{C}-\mathrm{J}}$ and $T_{\mathrm{C}-\mathrm{J}}$, respectively. The detonation products expand in the divergent nozzle and produce thrust. In this study, only the thrust produced by pressure is considered, while the frictional resistance is not considered.

The C-J detonation engine can operate steadily when the detonation velocity equals to the velocity of incoming flow in the isolator $\left(D_{\mathrm{C}-\mathrm{J}}=U_{1}\right)$. If the detonation velocity is faster than the incoming flow, it will propagate upstream out of the inlet of aircraft and cause the engine unstart. Otherwise, the flame will be blown out. The gas in the C-J detonation engine is combustible mixture. But the gas in the isolator of scramjets is air. It will mix with fuel and become premixed combustible mixture at the entrance of the combustor. The mixing process of the fuel and air in the isolator is ignored in the C-J detonation engine. For scramjets, the formation of C-J detonation in the combustor will decay in the isolator. However, in reality, the length of the isolator is so short that this process can be ignored.

The C-J detonation is the strongest combustion wave caused only by combustion. The Mach number of detonation products relative to the detonation front is unity. This means that the C-J detonation is a thermal choking flow. Therefore, the pressure of detonation products is the most important parameter for thrust of scramjet engines. And the C-J detonation velocity is the most important parameter for the steadiness of the supersonic flow field. In the following part, the crucial parameters influencing the $\mathrm{C}-\mathrm{J}$ detonation pressure and velocity are studied theoretically and the aerodynamic design principles of shock-induced combustion ramjet engines are deduced according to the analytical results.

\subsection{Theoretical results}

In the theoretical analysis, the combustible mixture is chosen to be $\mathrm{H}_{2}$ /air mixture with different equivalent ratio $(\phi)$. The $\mathrm{H}_{2}$ /air mixture is usually used in flight experiments such as X-43A and HyShot II. Hydrogen is the most favorable fuel for scramjets because its ignition delay time is very short. The short ignition delay time is very important for oblique detonation initiation. The static pressure of mixture in the isolator is assumed to be $101,325 \mathrm{~Pa}$ (1 atm). The static temperature in the isolator is varied from $300 \mathrm{~K}$ to $1500 \mathrm{~K}$ to simulate different compression conditions of the inlet. The parameters of stoichiometric $\mathrm{H}_{2}$ /air C-J detonation under different initial temperature are calculated by using classical C-J detonation theory. The parameters include C-J detonation 


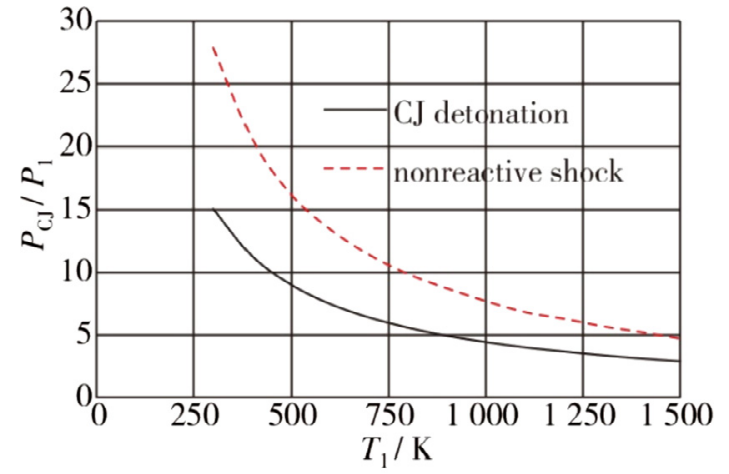

(a)

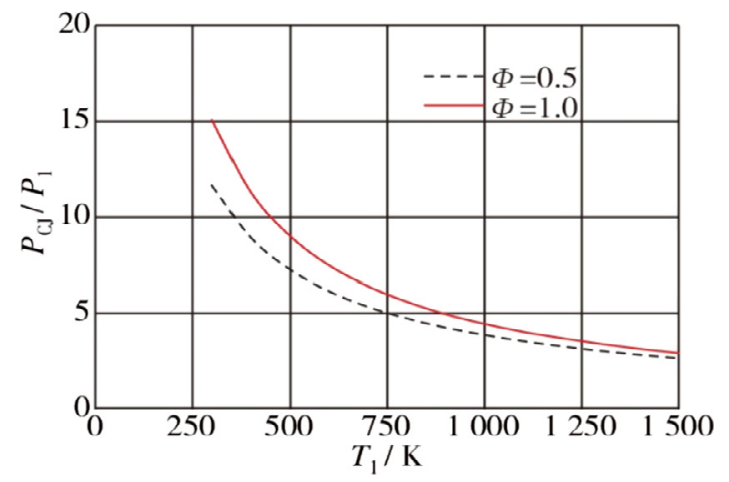

(b)

Fig. 3. Variation of pressure ratio with initial temperature under different conditions. (a) Stoichiometric $\mathrm{H}_{2}$ /air C-J detonation and nonreactive shock wave $\phi=1.0$. (b) Different equivalence ratios $\phi=1.0$ and 0.5 .

Mach number $M_{\mathrm{C}-\mathrm{J}}$, C-J detonation velocity $D_{\mathrm{C}-\mathrm{J}}$, and pressure ratio $P_{\mathrm{C}-\mathrm{J}} / P_{1}$.

The combustion pressure is a crucial parameter to predict the propulsive performance of scramjets. The pressure ratio $P_{\mathrm{C}-\mathrm{J}} / P_{1}$ of C-J detonation at different initial static temperature and different equivalent ratio are plotted in Fig. 3. From Fig. 3a, it can be found that the pressure ratio $P_{\mathrm{C}-\mathrm{J}} / P_{1}$ of $\mathrm{C}-\mathrm{J}$ detonation decreases exponentially with the increase of the initial static temperature. The pressure ratio is very sensitive to the initial static temperature. The main reason is that $\mathrm{C}$-J detonation can be considered as constantvolume combustion. The pressure ratio is $P_{\mathrm{C}-\mathrm{J}} / P_{1}=15.08$ at initial static temperature of $300 \mathrm{~K}$; the pressure ratio is $P_{\mathrm{C}-\mathrm{J}} / P_{1}=4.46$ at $1000 \mathrm{~K}$; and the pressure ratio is only $P_{\text {C-J }} / P_{1}=2.93$ at $1500 \mathrm{~K}$. This is the upper limit of pressure ratio obtained by supersonic combustion. This means that the propulsive performance of scramjet engines becomes worse with the increase of the air temperature at the entrance of the combustor. Therefore, in order to achieve a better performance, the intake flow static temperature in the isolator should be kept lower.

The pressure ratios at different equivalence ratios are plotted and compared in Fig. 3b. The equivalence ratios are $\phi=1.0$ and 0.5 , respectively. The surprising result is that the equivalence ratio has a small effect on the pressure ratio for $\mathrm{H}_{2}$ /air combustible mixture, especially at high initial temperature. For example, at $T_{1}=1000 \mathrm{~K}$, the pressure ratio $P_{\mathrm{C}-\mathrm{J}} / P_{1}=4.46$ for $\phi=1.0$ and $P_{\mathrm{C}-\mathrm{J}} / P_{1}=3.89$ for $\phi=0.5$, respectively. At initial static temperature of $T_{1}=1500 \mathrm{~K}$, the pressure ratio $P_{\mathrm{C}-\mathrm{J}} / P_{1}=2.93$ for $\phi=1.0$ and $P_{\mathrm{C}-\mathrm{J}} / P_{1}=2.67$ for $\phi=0.5$, respectively. This means that we can save the fuel consumption of scramjets by reducing the equivalence ratio while keeping its pressure ratio almost unchanged.

The pressure ratio of $\mathrm{C}-\mathrm{J}$ detonation waves and nonreactive shock waves at the same Mach number are also compared in

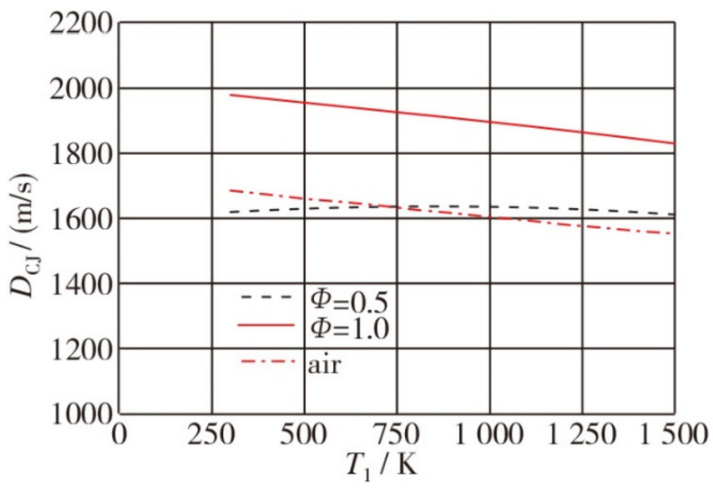

Fig. 4. Detonation velocity of stoichiometric $\mathrm{H}_{2}$ /air C-J detonation under different initial temperature and different equivalence ratio.

Fig. 3a. The Mach number is the C-J detonation Mach number at different initial static temperature. The equations are given as

$\frac{P_{\mathrm{C}-\mathrm{J}}}{P_{1}}=\frac{\gamma_{1}}{\gamma_{2}+1} M_{\mathrm{C}-\mathrm{J}}^{2}$

$\frac{P_{2}}{P_{1}}=\frac{2 \gamma_{1}}{\gamma_{1}+1} M_{1}^{2}$

where, the terms $P_{1}$ and $P_{2}$ are the initial static pressure and pressure behind the normal shock wave, respectively. $P_{C-\mathrm{J}}$ is the $C_{-} \mathrm{J}$ detonation pressure. The terms $\gamma_{1}$ and $\gamma_{2}$ are the specific heat ratio of reactants and detonation products, respectively. We can also find from Fig. 3a that at the same Mach number, the pressure ratio across a normal shock wave is about two times of that of C-J detonation. This means that for a dual-mode scramjet engine, if it operates at the ramjet mode, a shock wave is produced and kept in the isolator. This shock wave increases the pressure of air in the isolator to a high value, but is also increases the static temperature at the entrance of the combustor. The equation is given as

$\frac{T_{2}}{T_{1}}=\frac{7\left(M_{1}^{2}-1\right)\left(M_{1}^{2}+5\right)}{36 M_{1}^{2}}$

where, the terms $T_{1}$ and $T_{2}$ are the initial static temperature and temperature behind the normal shock wave, respectively. As a result, the pressure ratio after combustion is decreased because of the higher initial static temperature. This means that the scramjets will produce almost the same thrust no matter it operates at scramjet mode or ramjet mode.

The shock wave velocity is a crucial parameter to predict the steadiness of the combustion flow field of scramjets. Fig. 4 shows the detonation velocity at different initial temperature and equivalence ratio. The shock wave velocity of air with the same Mach number as C-J detonation is also plotted in this figure. From Fig. 4 we can find that the detonation velocity decreases slowly as the initial temperature increases. The detonation velocity is $1979 \mathrm{~m} / \mathrm{s}$ at initial temperature of $300 \mathrm{~K}$ and $1830 \mathrm{~m} / \mathrm{s}$ at $1500 \mathrm{~K}$, respectively. This result shows that the detonation velocity is insensitive to the initial temperature. The velocity of shock wave in the air with the same Mach number is about $300 \mathrm{~m} / \mathrm{s}$ slower than that of C-J detonation. The reason is that the sound speed of air is lower than that of the $\mathrm{H}_{2}$ /air mixture.

These results indicate that if the detonation wave propagates upstream into the air in the isolator, it will propagate rapidly to the inlet of scramjets and cause the engine unstart because its velocity is about $300 \mathrm{~m} / \mathrm{s}$ faster than the velocity of the incoming flow. Suppose the length of the isolator is $1 \mathrm{~m}$, it takes about $3.3 \mathrm{~ms}$ for the shock wave to travel to the inlet and the oscillation frequency is about $300 \mathrm{~Hz}$. If the shock wave attenuates and 


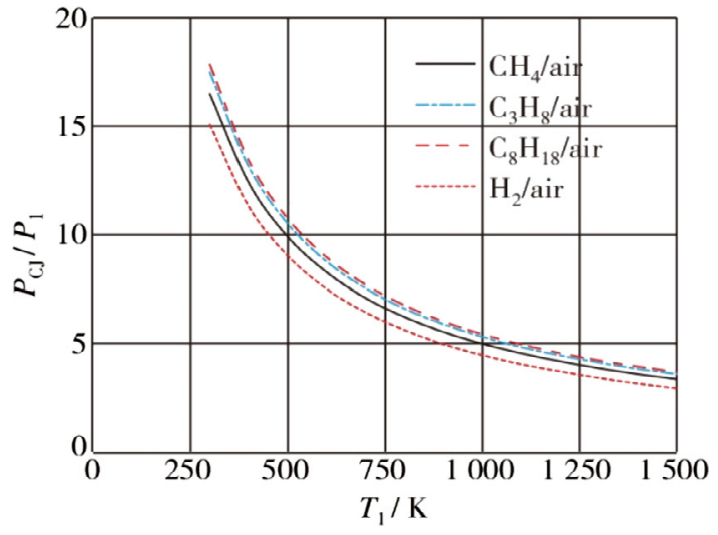

(a)

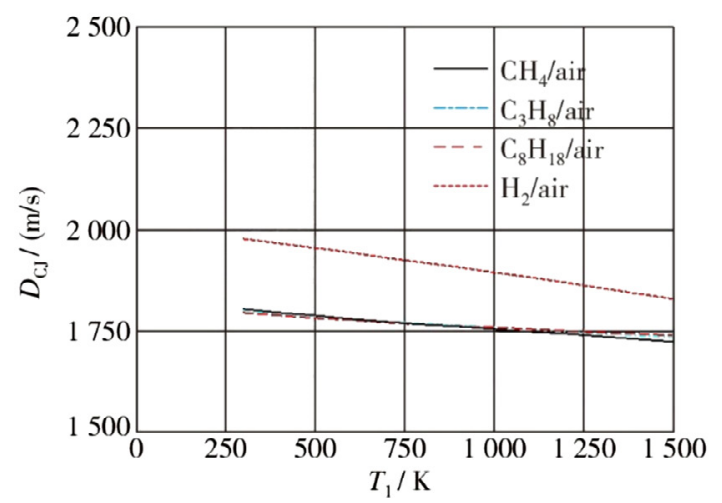

(b)

Fig. 5. Detonation pressure ratio and velocity of stoichiometric hydrocarbon fuels under different initial temperature (a) pressure ratio (b) detonation velocity.

stays steadily in the isolator, the engine will operate in the ramjet mode. In the ramjet mode, the leading shock wave in the isolator further increases the pressure and temperature at the entrance of combustor. As a result, the pressure ratio after combustion will decrease because of the higher initial temperature and the flow field becomes more unsteady because the velocity in the isolator decreases.

In order to make the flow field of scramjet engines steady, the velocity of C-J detonation should be decreased. There are some effective ways to decrease the velocity of C-J detonation, for example, (1) to reduce the equivalence ratio, (2) to use a divergent combustor, (3) to use a distributed heat release configuration. The velocity of $\mathrm{H}_{2}$ /air C-J detonation at the equivalence ratio $\phi=0.5$ at different initial temperature is plotted in Fig. 4 for comparison. From Fig. 4 , it can be seen that the detonation velocity at $\phi=0.5$ is almost the same as that of air in the isolator. As a result, the flow field of scramjets becomes steady for this case of $\phi=0.5$ but becomes unsteady for this case of $\phi=1.0$. The essence of reducing equivalence ratio, using divergent combustor and using distributed heat release configuration is to reduce the strength of the shock wave produced by supersonic combustion.

The type of fuel is another important issue for scramjets. The propulsive performance of hydrocarbon fuels is shown in Fig. 5. The hydrocarbon fuels are $\mathrm{CH}_{4}, \mathrm{C}_{3} \mathrm{H}_{8}$ and $\mathrm{C}_{8} \mathrm{H}_{18}$, respectively. The results of $\mathrm{H}_{2}$ /air are also plotted for comparison. From Fig. 5a, it can be found that the pressure ratio of stoichiometric hydrocarbon/air $\mathrm{C}$-J detonation is higher than that of $\mathrm{H}_{2}$ /air, which means that hydrocarbon can produce more thrust than hydrogen. In addition, the C-J detonation velocity is about $200 \mathrm{~m} / \mathrm{s}$ slower than that of hydrogen/air (see Fig. 5b), which means that the flow field of hydrocarbon/air is more stable than $\mathrm{H}_{2}$ /air. These results indicate that hydrocarbon is better than hydrogen for scramjets, in cases where pressure ratio and detonation velocity are the only consideration. However, the ignition delay time of hydrocarbon/air is one or two orders longer than that of $\mathrm{H}_{2}$ /air, which means that hydrocarbon is very difficult to ignite. Therefore, the hydrogen is better than hydrocarbon from this perspective. This is beyond the scope of this paper.

\subsection{Aerodynamic design principles of shock-induced combustion ramjet engines}

Based on the above theoretical analysis results and some previous researches [11,12], five aerodynamic design principles for scramjets and shock-induced combustion ramjet engines are put forth as follows.

(1) The incoming flow velocity at the entrance of combustor should be faster than the C-J detonation velocity of the mixture to avoid the shock wave propagating upstream in the isolator. In other words, the C-J detonation velocity of the mixture in the combustor should be slower than the incoming flow velocity.

(2) The temperature behind the main oblique shock wave should be considered together with its ignition delay time to make sure that the oblique detonation initiation occurs. The static pressure, static temperature and equivalence ratio are three main parameters influencing the ignition delay time. And the ignition delay time is very sensitive to static temperature. In this paper, the ignition temperature of $\mathrm{H}_{2}$ /air mixture at $0.5 \mathrm{MPa}$ is considered to be $1400 \mathrm{~K}$.

(3) The static temperature in the isolator should be as low as possible to increase the pressure ratio of combustion in order to increase its thrust. This means that the active cooling of the incoming flow in the isolator can increase the thrust of scramjets.

(4) The method of boundary layer bleeding should be taken to avoid boundary layer separation. Once boundary layer separates, new oblique shock waves will appear in front of the separation bubbles. The shock-shock interaction and shock-boundary layer interaction will increase the strength of the shock wave in the isolator and make the flow field unsteady and oscillate.

(5) Thermal choking should be avoided. On the one hand, thermal choking will produce a C-J detonation. On the other hand, the scramjet engines usually have divergent combustors and nozzles. If thermal choking occurs, the divergent combustor and nozzle become a diffuser. The velocity of the subsonic flow decreases and the pressure increases, which will enhance the strength of the shock wave.

In the next section, a two-dimensional numerical simulation of a shcramjet is conducted to verify the previous analysis results. The geometry of the shcramjet is designed according to the principles. There are theoretical solutions for one-dimensional thermal choking and C-J detonation. However, there is no theoretical solution to analyze the influence of boundary layer separation or geometry variation. Therefore, the C-J detonation is considered as a design baseline. The two-dimensional simulation is adequate for verifying the principles.

\section{Numerical simulation of shock-induced combustion ramjet engines}

\subsection{Geometry of shock-induced combustion ramjet engines}

The shock-induced combustion ramjet (shcramjet) engines or oblique detonation engines (ODEs) are more potential for hypersonic flight (Mach number above nine) because the total enthalpy of the hypersonic flow is high enough to initiate the oblique detonation [23]. The key combustion mechanism is the auto-ignition of 


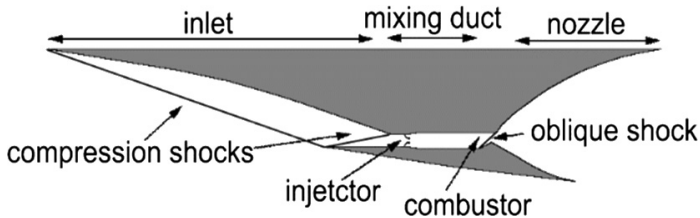

Fig. 6. The schematic of shock-induced combustion ramjet engines.

the reactants heated by oblique shock waves. In this case, the turbulence, diffusion, viscous, and heat conduction processes in ODEs are less important than that of scramjets. This is the main difference between shcramjets and scramjets.

Fig. 6 shows the schematic of Shcramjets. It consists of four parts: the inlet, the mixing duct, the combustor and thrust nozzle. The hydrogen fuel is injected at the entrance of the mixing duct and mixes with the supersonic airflow compressed by the inlet. In the combustor, a wedge generates an oblique shock wave, which ignites the combustible gases and induces an oblique detonation wave. This combustion process is also called shock-induced combustion $[23,24]$.

Based on the above aerodynamic design principles, a simplified oblique detonation engine was designed and two-dimensional numerical simulations were conducted. The aim of the numerical simulations is to study the combustion flow field of Shcramjets. The configuration and computational domain of the Shcramjets is shown in Fig. 7. The total length of the full-scale aircraft is $5023 \mathrm{~mm}$. The intake ramp has a length $\left(\mathrm{L}_{1}\right)$ of $2524 \mathrm{~mm}$ and an angle of $13^{\circ}$. A boundary layer bleeding channel is added at the end of the intake ramp to reduce shock-boundary layer interaction. The mixing duct has a height (h) of $60 \mathrm{~mm}$ and an expanded angle of $5^{\circ}$. Two triangle injectors are located in the mixing duct and either of them has a height of $3 \mathrm{~mm}$ and an angle of $5^{\circ}$. The wedge in the combustor has an angle of $20^{\circ}$. The thrust nozzle has a length $\left(\mathrm{L}_{3}\right)$ of $1597 \mathrm{~mm}$ and an expanded angle of $20^{\circ}$.

\subsection{Operating conditions and numerical methods}

The freestream conditions duplicate the flight conditions at an altitude of $40 \mathrm{~km}$ with a static pressure of $250 \mathrm{~Pa}$ and a static temperature of $287 \mathrm{~K}$. The flight Mach number is M9 and the angle of attack is zero degree. The gaseous hydrogen with a total temperature of $900 \mathrm{~K}$ is injected from two sonic fuel injectors. The fuel equivalence ratio is controlled by adjusting the hydrogen static pressure. All wall boundaries are assumed to be no-slip, noncatalytic and isothermal at $300 \mathrm{~K}$.

The numerical simulation has been performed using unsteady compressible form of RANS equations closed by the shear-stress transport (SST) $k-\omega$ turbulence model. The governing equations are shown as followed in Cartesian tensor notation.

Continuity:

$\frac{\partial \rho}{\partial t}+\frac{\partial}{\partial x_{i}}\left(\rho u_{i}\right)=0$

$$
\text { Momentum: }
$$

$\frac{\partial}{\partial t}\left(\rho u_{i}\right)+\frac{\partial}{\partial x_{j}}\left(\rho u_{i} u_{j}\right)=-\frac{\partial p}{\partial x_{i}}+\frac{\partial}{\partial x_{i}}\left(\tau_{i j}\right)$

Energy:

$\frac{\partial}{\partial t}(\rho E)+\frac{\partial}{\partial x_{i}}\left(u_{i}(\rho E+p)\right)=\frac{\partial}{\partial x_{i}}\left[\left(\alpha+\alpha_{t}\right) \frac{\partial T}{\partial x_{i}}+u_{j}\left(\tau_{i j}\right)\right]$

where, $\rho$ is the density, $p$ is the static pressure, $u_{i}$ is the velocity components, $\alpha$ is the thermal conductivity, $\alpha_{t}$ is the turbulent conductivity, $E$ and $T$ are the mass-averaged energy and static temperature. The term $\tau_{i j}$ is the stress tensor and it is defined as followed.

$\tau_{i j}=\mu_{e f f}\left(\frac{\partial u_{i}}{\partial x_{j}}+\frac{\partial u_{j}}{\partial x_{i}}-\frac{2}{3} \delta_{i j} \frac{\partial u_{k}}{\partial x_{k}}\right)$

where, $\mu_{e f f}$ is effective viscosity and $\delta_{i j}$ is the Kronecker symbol.

The state equation of ideal gas is shown as followed.

$p=\rho R_{C} T$

where, $R_{c}$ is the gas constant.

The SST $k-\omega$ turbulence model has been used in the calculation. The transport equations of turbulence kinetic energy $(k)$ and specific dissipation rate $(\omega)$ have been defined as followed.

$$
\begin{aligned}
& \frac{\partial}{\partial t}(\rho k)+\frac{\partial}{\partial x_{i}}\left(\rho k u_{i}\right)=\frac{\partial}{\partial x_{j}}\left(\Gamma_{k} \frac{\partial k}{\partial x_{j}}\right)+G_{k}-Y_{k} \\
& \frac{\partial}{\partial t}(\rho \omega)+\frac{\partial}{\partial x_{i}}\left(\rho \omega u_{i}\right)=\frac{\partial}{\partial x_{j}}\left(\Gamma_{\omega} \frac{\partial \omega}{\partial x_{j}}\right)+G_{\omega}-Y_{\omega}+D_{\omega}
\end{aligned}
$$

where $G_{k}$ and $G_{\omega}$ represent the generation of $k$ and $\omega$ due to mean velocity gradients. $\Gamma_{k}$ and $\Gamma_{\omega}$ represent the effective diffusivity of $k$ and $\omega$, respectively. $Y_{k}$ and $Y_{\omega}$ represent the dissipation of $k$ and $\omega$ owing to turbulence. $D_{\omega}$ is the cross-diffusion term.

The convective terms were solved by using a second-order upwind scheme. The transient formulation was solved by the semi-implicit method. The $\mathrm{H}_{2}$ /air combustion mechanism is the 9-species and 19-reactions detailed chemical kinetics of Gerlinger [25]. It is a nine-species $\left(\mathrm{N}_{2}, \mathrm{O}_{2}, \mathrm{H}_{2}, \mathrm{H}_{2} \mathrm{O}, \mathrm{OH}, \mathrm{O}, \mathrm{H}, \mathrm{HO}_{2}\right.$, and $\mathrm{H}_{2} \mathrm{O}_{2}$ ), 19-reactions modified reaction scheme based on the chemical kinetics models of Jachimowski [26].

Three grid densities were investigated for grid convergence study. Temperature along the same streamline of three grid densities are displayed in Fig. 8. The standard grid has 7.7 million cells with $\mathrm{a} \mathrm{y}^{+}$of about 1.0. The fine grid and course grid have 4.1 million cells and 13.4 million cells, respectively. The difference between the fine grid and standard grid was quite small and both grid densities have similar trends. The standard grid is chosen for simulation. For the transient formulation, a time step of $5 \times 10^{-8} \mathrm{~s}$ has been performed in the calculation.

Before the numerical simulations, the numerical methods were validated through the ground-based testing of HyShot II scramjet in the High Enthalpy Shock Tunnel Göttingen (HEG) of the German Aerospace Center (DLR) [27] (Details of HyShot II and the freestream conditions of HEG can be found in Ref. [27] and Ref. [28]). Fig. 9 shows our CFD results, experimental data and computational results of DLR, where $p$ and $q$ are surface pressure and wall heat flux. Our CFD results are in good agreement with the experimental data although there is a little difference between measured and computed wall heat flux distributions. Therefore, this numerical scheme is capable for numerical simulations of supersonic combustion flow.

\subsection{Results and discussion}

The pressure contours of the full-scale shcramjets at $\phi=0.57$ are shown in Fig. 10. Fig. 10b clearly shows the shock trains caused by injectors and expanded mixing duct. The steady flow field at $\phi=0.57$ is obtained. The incoming flow comes into the mixing duct through two oblique shock waves. Positions of the compression shock waves are close to the inviscid design. The theoretical values have a pressure of $11,456 \mathrm{~Pa}$, a temperature of $976 \mathrm{~K}$ and a velocity of $2576 \mathrm{~m} / \mathrm{s}$. The Mach number of theoretical values is 4.11. The boundary layer spills out from the boundary bleed channel and this measure can effectively eliminate the influence of 


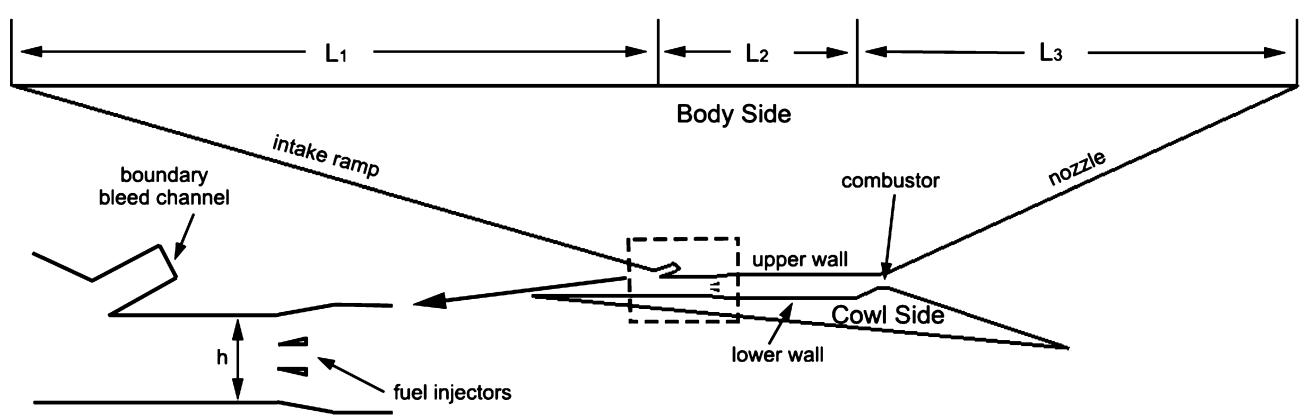

Fig. 7. The configuration and details of the simplified shock-induced combustion ramjet engine designed according to the principles.

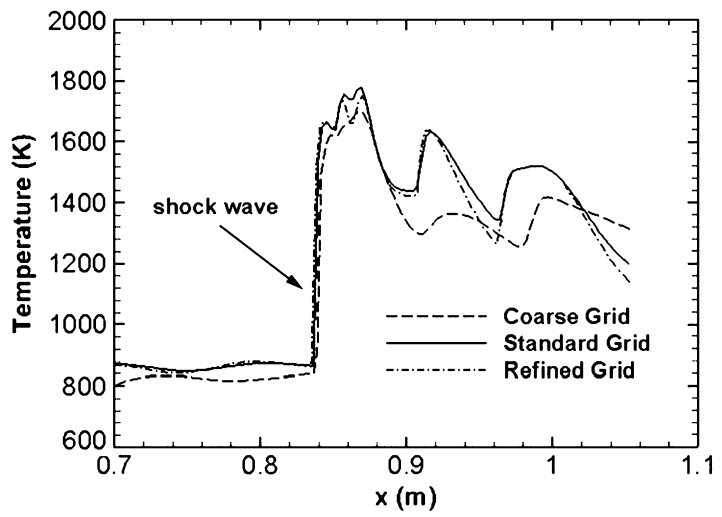

Fig. 8. Grid convergence of temperature along streamlines through the same point.

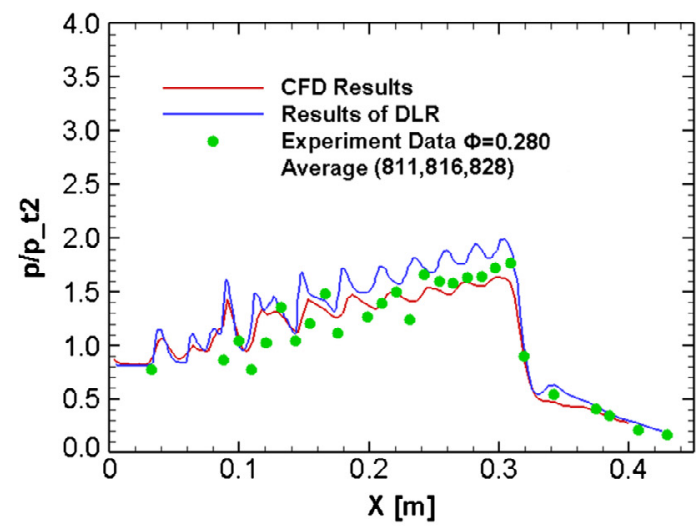

(a)

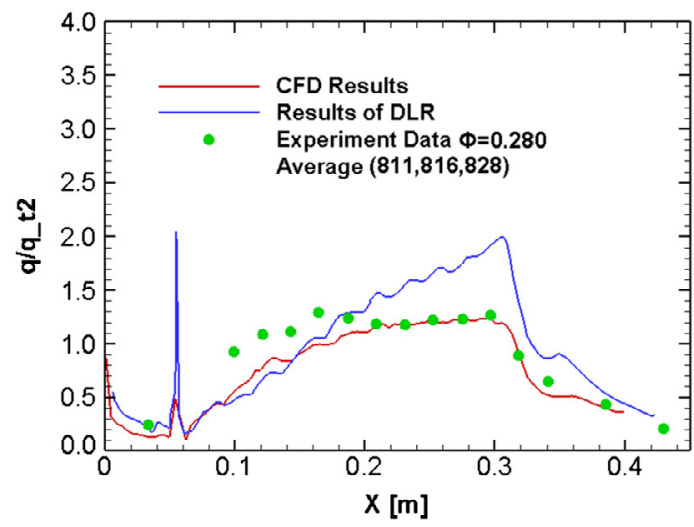

(b)

Fig. 9. Normalized surface pressure (a) and wall heat flux (b) of the lower combustor wall; The numbers in parentheses denote the run numbers of HyShot II ground test [27].

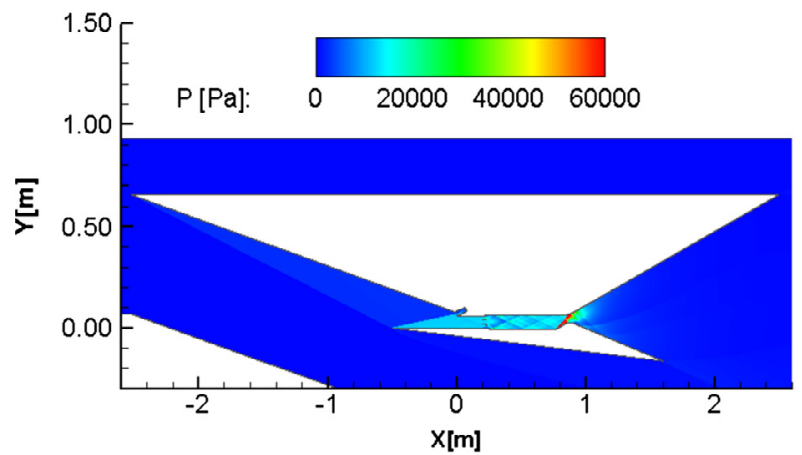

(a)

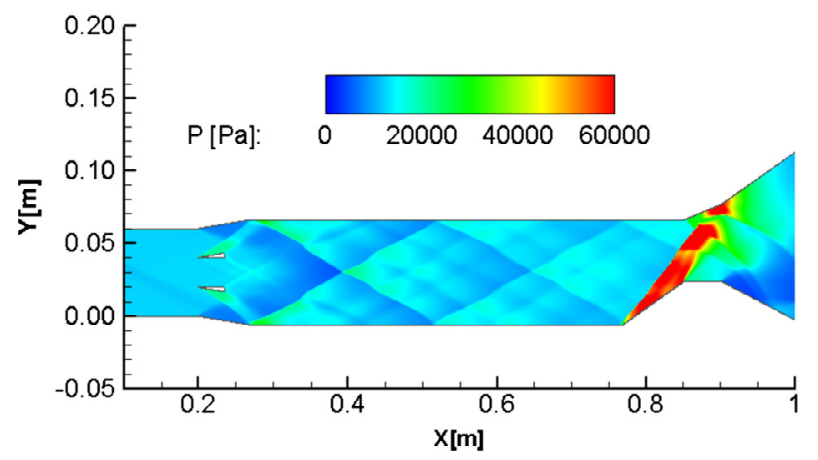

(b)

Fig. 10. The pressure contours of (a) the whole shcramjet model and (b) the mixing duct.

shock wave-boundary layer interaction. It ensures that the mainstream in the mixing duct has uniform velocity and temperature. The x-velocity component at the mixing duct entrance is faster than the C-J detonation velocity of stoichiometric $\mathrm{H}_{2}$ /air mixture which is $1950 \mathrm{~m} / \mathrm{s}$. According to the above principles, the oblique shock wave stands in front of the wedge and the flow field keeps steady.

The detailed flow field of the combustor is shown in Fig. 11. From Fig. 11, it can be found that shock-induced boundary layer separates at the upper wall of the combustor and a small separation bubble is produced. A new oblique shock wave appears in front of the separation bubble and leads to a shock-shock interaction. However, the whole flow field does not be influenced by the boundary layer separation because of the divergent nozzle, which expands the combustion products to lower pressure.

The parameters along the streamline in Fig. 11a are extracted for a further study. The parameters include pressure $(P)$, temperature $(T)$, mass fraction of $\mathrm{H}_{2}\left(\left[\mathrm{H}_{2}\right]\right)$, mass fraction of $\mathrm{H}_{2} \mathrm{O}\left(\left[\mathrm{H}_{2} \mathrm{O}\right]\right)$ and mass fraction of $\mathrm{OH}([\mathrm{OH}])$. Fig. 12 shows the profiles of different normalized parameters, where $P^{*}=60 \mathrm{kPa}, T^{*}=1600 \mathrm{~K}$, 


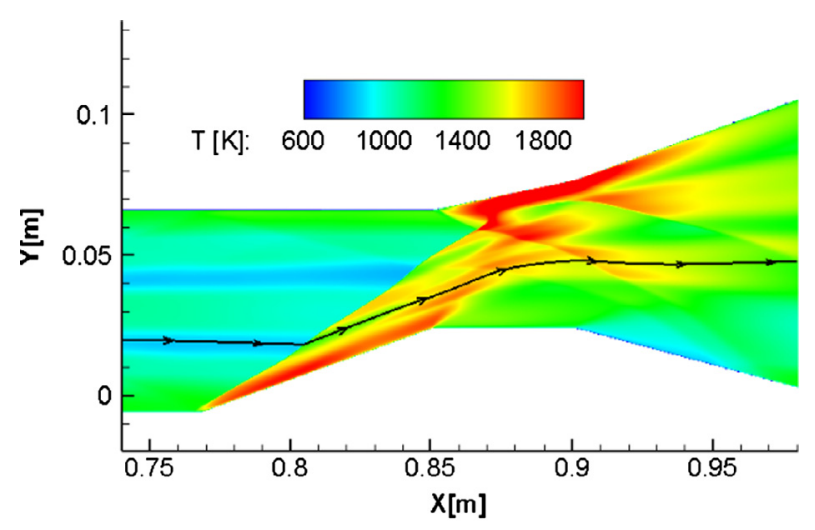

(a)

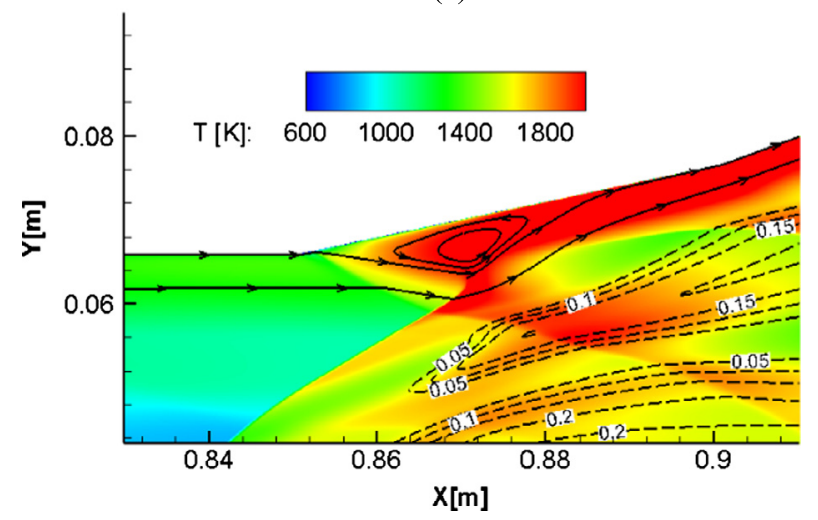

(b)

Fig. 11. The temperature contours (a) and local enlarged contours (b) in the combustor with $\phi=0.57$; streamlines: solid lines; mass fraction of $\mathrm{H}_{2} \mathrm{O}$ : numbers and dashed isolines.

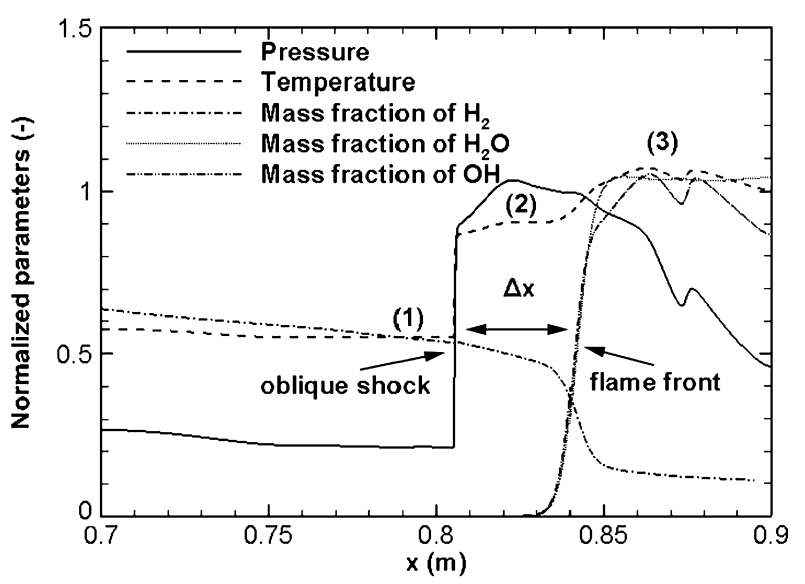

Fig. 12. Normalized parameters along the streamline in Fig. 13b. Normalized pressure $P / P^{*}$, normalized temperature $T / T^{*}$, normalized mass fraction of $\mathrm{H}_{2}\left[\mathrm{H}_{2}\right] /\left[\mathrm{H}_{2}\right]^{*}$, normalized mass fraction of $\left[\mathrm{H}_{2} \mathrm{O}\right] /\left[\mathrm{H}_{2} \mathrm{O}\right]^{*}$, normalized mass fraction of $\mathrm{OH}[\mathrm{OH}] /[\mathrm{OH}]^{*}$.

$\left[\mathrm{H}_{2}\right]^{*}=0.12,\left[\mathrm{H}_{2} \mathrm{O}\right]^{*}=0.2$ and $[\mathrm{OH}]^{*}=0.012$. Fig. 13 shows the ignition delay time of the detailed chemical kinetics. The curve of ignition delay time at $P=0.2 \mathrm{MPa}$ agrees well with the experimental data. The static temperature and pressure behind the main oblique shock wave is about $1500 \mathrm{~K}$ and $50 \mathrm{kPa}$, respectively. The ignition delay time under this condition is $\tau_{i g}=20 \mu \mathrm{s}$, which can be found in Fig. 13. The flow velocity is $u=1800 \mathrm{~m} / \mathrm{s}$ behind the oblique shock wave. Meanwhile, the induction distance between the shock wave and the flame front is $\Delta x=0.036 \mathrm{~m}$ (see Fig. 12). The induction distance equals to the product of the ignition delay

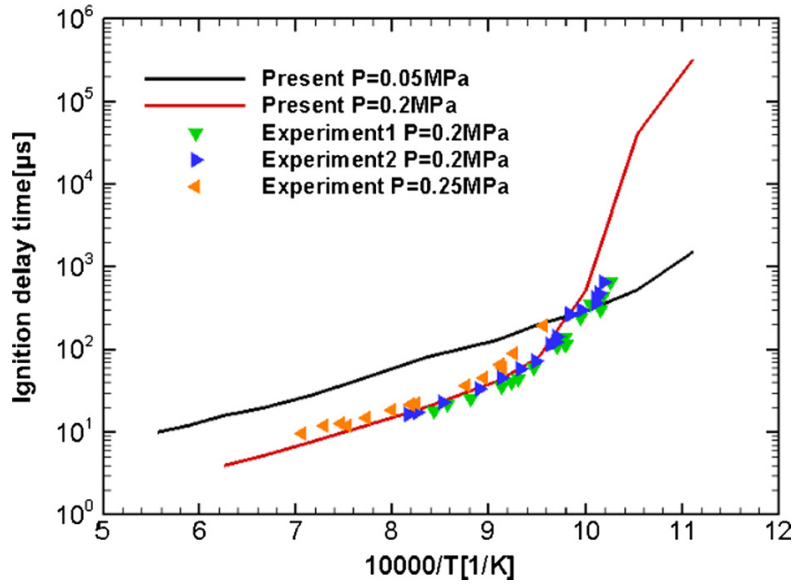

Fig. 13. The ignition delay time of chemical kinetics of Gerlinger [25].

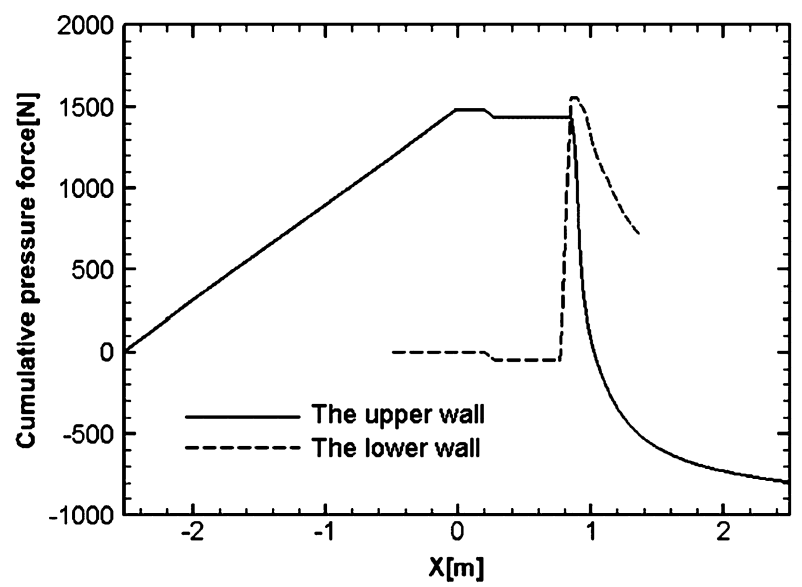

(a)

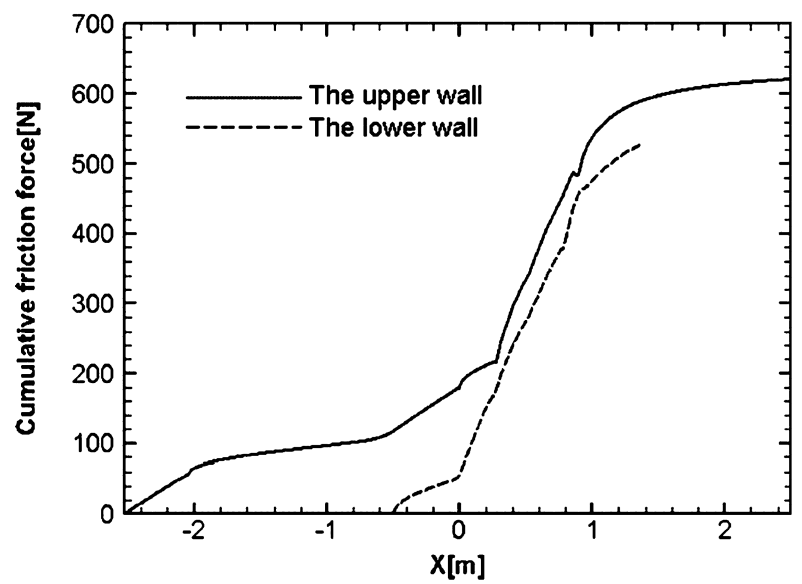

(b)

Fig. 14. Cumulative pressure forces (a) and cumulative friction forces (b).

time and flow velocity. The numerical results agree very well with the analytical results.

Meanwhile, the curves of the cumulative pressure and frictional forces (exclude the boundary bleeding channel) in the x-direction of the internal walls (include the upper side and lower side) are presented in Fig. 14. The cumulative forces are defined as an integral of the local surface pressure and the local wall angle, where the length in the $z$-direction is set to be $1.0 \mathrm{~m}$. The results indicate that the combustion-inducing wedge generates $52.0 \%$ of pressure drag, $6.0 \%$ of friction drag and $39.5 \%$ of total drag although its 
length is only $2.15 \%$ of total length. The shock-induced combustion finally generates a net thrust of $791 \mathrm{~N}$ during the whole process. These are the primary results of this simplified configuration. The configuration and thrust performance need further optimization because the main purpose of this paper is to study the combustion flow fields of scramjets and Shcramjets.

\section{Conclusions}

In this paper, the C-J detonation theory is firstly used to analyze the flow field of scramjets. This theory can predict the pressure in the combustor of scramjets and the shock wave propagating upstream in the isolator when the combustion flow field is thermal choking. Some useful and general conclusions are obtained by the theoretical analysis. On the basis of theoretical analysis, aerodynamic design principles for scramjets and shock-induced combustion ramjet engines are put forth. A full-scale shock-induced combustion ramjet engine is designed according to these principles. Two-dimensional numerical simulations are conducted to study the flow field of this engine at M9, $40 \mathrm{~km}$ altitude and equivalence ratio of unity. Steady flow field is obtained which demonstrate the correctness of the aerodynamic design principles.

\section{Declaration of competing interest}

The authors declare that they have no known competing financial interests or personal relationships that could have appeared to influence the work reported in this paper.

\section{Acknowledgements}

This study is founded by the National Natural Science Foundation of China (No. 11672312 \& No. 11532014).

\section{References}

[1] A. Ferri, Review of problems in application of supersonic combustion, Aeronaut. J. 68 (645) (1964) 575-597.

[2] A. Ferri, Review of scramjet propulsion technology, J. Aircr. 5 (1) (1968) 3-10.

[3] E.T. Curran, Scramjet engines: the first forty years, J. Propuls. Power 17 (6) (2001) 1138-1148.

[4] J.W. Kim, O.J. Kwon, Modeling of incomplete combustion in a scramjet engine, Aerosp. Sci. Technol. 78 (2018) 397-402.

[5] Z. Ren, B. Wang, B. Hu, et al., Numerical analysis of supersonic flows over an Aft-ramped open-mode cavity, Aerosp. Sci. Technol. 78 (2018) 427-437.

[6] J. Shin, H.G. Sung, Combustion characteristics of hydrogen and cracked Kerosene in a DLR scramjet combustor using hybrid RANS/LES method, Aerosp. Sci. Technol. 80 (2018) 433-444.
[7] D. Scherrer, O. Dessornes, M. Ferrier, et al., Research on supersonic combustion and scramjet combustors at ONERA, J. Aerosp. Lab. 11 (2016) 1-19.

[8] H.D. Shen, Y.B. Liu, B.Y. Chen, Control-relevant modeling and performance limitation analysis for flexible air-breathing hypersonic vehicles, Aerosp. Sci. Technol. 76 (2018) 340-349.

[9] R.J. Clark, S.B. Shrestha, A review of numerical simulation and modeling of combustion in scramjets, proceedings of the institution of mechanical engineers, part G, J. Aerosp. Eng. 229 (5) (2015) 958-980.

[10] T. Mitani, K. Tani, H. Miyajima, Flow choking by drag and combustion in supersonic engine testing, J. Propuls. Power 23 (6) (2007) 1177-1184.

[11] S.J. Laurence, D. Lieber, J.M. Schramm, et al., Incipient thermal choking and stable shock-train formation in the heat-release region of a scramjet combustor part I: shock-tunnel experiments, Combust. Flame 162 (4) (2015) 921-931.

[12] J. Larsson, S. Laurence, I.B. Moreno, et al., Incipient thermal choking and stable shock-train formation in the heat-release region of a scramjet combustor. Part II: large eddy simulations, Combust. Flame 162 (4) (2015) 907-920.

[13] J.Y. Oh, F. Ma, S.Y. Hsieh, V. Yang, Interactions between shock and acoustic waves in a supersonic inlet diffuser, J. Propuls. Power 21 (3) (2005) 486-495.

[14] H.S. Tsien, M. Beilock, Heat source in a uniform flow, J. Aeronaut. Sci. 16 (12) (1949) 756-757.

[15] C. Birzer, C.J. Doolan, Quasi-one-dimensional model of hydrogen-fueled scramjet combustors, J. Propuls. Power 25 (6) (2009) 1220-1225.

[16] T.F. O’Brien, R.P. Starkey, M.J. Lewis, Quasi-one-dimensional high-speed engine model with finite-rate chemistry, J. Propuls. Power 17 (6) (2001) 1366-1374.

[17] T. Vanyai, M. Bricalli, S. Brieschenk, et al., Scramjet performance for ideal combustion processes, Aerosp. Sci. Technol. 75 (2018) 215-226.

[18] E. Curran, W. Heiser, D. Pratt, Fluid phenomena in scramjet combustion systems, Annu. Rev. Fluid Mech. 28 (1996) 323-360.

[19] S.J. Laurence, S. Karl, J.M. Schramm, K. Hannemann, Transient fluid combustion phenomena in a model scramjet, J. Fluid Mech. 722 (2013) 85-120.

[20] S. O’Byrne, M. Doolan, S.R. Olsen, A.F.P. Houwing, Analysis of transient thermal choking processes in a model scramjet engine, J. Propuls. Power 16 (5) (2000) $808-814$.

[21] Y.F. Liu, H. Shen, D.L. Zhang, Z.L. Jiang, Theoretical analysis on deflagration to detonation transition, Chin. Phys. B 27 (8) (2018) 084703.

[22] H. Shen, Z.J. Zhang, Y.F. Liu, Z.L. Jiang, Analysis on the propulsion performance of scramjet engines, Phys. Gases 3 (1) (2018) 12-19 (in Chinese).

[23] J. Chan, J.P. Sislian, D. Alexander, Numerically simulated comparative performance of a scramjet and shcramjet at Mach 11, J. Propuls. Power 26 (5) (2010) 1125-1134.

[24] D.C. Alexander, J.P. Sislian, Computational study of the propulsive characteristics of a shcramjet engine, J. Propuls. Power 24 (1) (2008) 34-44.

[25] P. Gerlinger, H. Möbus, D. Brüggemann, An implicit multigrid method for turbulent combustion, J. Comput. Phys. 167 (2001) 247-276.

[26] C.J. Jachimowski, An analytical study of the hydrogen-air reaction mechanism with application to scramjet combustion, NASA TP 2791, 1988.

[27] K. Hannemann, S. Karl, J.M. Schramm, J. Steelant, Methodology of a combined ground based testing and numerical modelling analysis of supersonic combustion flow paths, Shock Waves 20 (2010) 353-366.

[28] R. Pecnik, V.E. Terrapon, F. Ham, G. Iaccarino, H. Pitsch, Reynolds-averaged Navier-Stokes simulations of the HyShot II scramjet, AIAA J. 50 (8) (2012) 1717-1732. 